\title{
A knockdown of the herpes simplex virus type-1 gene in all-in-one CRISPR vectors
}

\author{
Nastaran Khodadad ${ }^{1,2^{*}}$, Mona Fani ${ }^{1,3^{*}}$, Saleh Jamehdor ${ }^{4}$, Rahil Nahidsamiei ${ }^{1,2}$, \\ Manoochehr Makvandi ${ }^{1,2}$, Saeed Kaboli ${ }^{5}$, Ali Teimoori ${ }^{1,2,6}$, Jose Thekkiniath ${ }^{7,8}$
}

${ }^{1}$ Cancer Research Center, Ahvaz Jundishapur University of Medical Sciences, Ahvaz, Iran

${ }^{2}$ Department of Virology, Ahvaz Jundishapur University of Medical Sciences, Ahvaz, Iran

${ }^{3}$ Department of Pathobiology and Laboratory Sciences, School of Medicine, North Khorasan

University of Medical Sciences, Bojnurd, Iran

${ }^{4}$ Department of Biology, Faculty of Sciences, University of Sistan and Baluchestan, Zahedan, Iran

${ }_{5}^{5}$ Department of Medical Biotechnology and Cancer Gene Therapy Research Center,

School of Medicine, Zanjan University of Medical Sciences, Zanjan, Iran

${ }^{6}$ Department of Virology, Faculty of Medicine, Hamadan University of Medical Sciences,

Hamadan, Iran

${ }^{7}$ Fuller Laboratories, Fullerton, CA, USA

${ }^{8}$ Department of Internal Medicine, Section of Infectious Diseases, Yale School of Medicine, New Haven, CT, USA

*Nastaran Khodadad and Mona Fani contributed equally to this work.

\begin{abstract}
Introduction. Herpes simplex virus type 1 (HSV-1) is a virus that causes serious human disease and establishes a long-term latent infection. The latent form of this virus has shown to be resistant to antiviral drugs. Clustered Regularly Interspace Short Palindromic Repeats (CRISPR), is an important tool in genome engineering and composed of guide RNA (gRNA) and Cas9 nuclease that makes an RNA-protein complex to digest exclusive target sequences implementation of gRNA. Moreover, CRISPR-Cas9 system effectively suppresses HSV-1 infection by knockout of some viral genes.

Materials and methods. To survey the efficacy of Cas9 system on HSV-1 genome destruction, we designed several guide RNAs (gRNAs) that all packaged in one vector. Additionally, we performed a one-step restriction using BamHI and Esp3I enzymes.

Results. CRISPR/Cas9 system targeted against the gD gene of HSV-1 was transfected into HEK-AD cells that showed a significant reduction of HSV-1 infection by plaque assay and real-time PCR.

Conclusion. The $p$ Cas-Guide-EF1a-GFP CRISPR vector can create a fast and efficient method for gRNA cloning by restriction enzymes (Esp3I (BsmBI) and BamHI). Therefore, the CRISPR/Cas9 system may be utilized for the screening of genes critical for the HSV-1 infection and developing new strategies for targeted therapy of viral infections caused by HSV-1. (Folia Histochemica et Cytobiologica 2020, Vol. 58, No. 3, 174-181)
\end{abstract}

Key words: CRISPR; Cas9; gRNA; genome editing; HSV-1; HEK-AD cells 


\section{Introduction}

Herpes simplex virus type 1 (HSV-1) is a very contagious and lifetime infectious pathogen and remains an important problem worldwide $[1,2]$. Herpes viruses are known to be involved in lytic infection in which viruses lyse their host cells or latent infection in which viruses remain silent within the host cells $[1,3]$.

In recent years, several studies have focused on DNA editing [4, 5] such as zinc-finger nucleases (ZFNs), transcription activator-like effector nucleases (TALENs) system. However, Clustered Regularly Interspace Short Palindromic Repeats (CRISPR) has been considered as an important acceptable system for genome editing [6]. CRISPR/Cas9 system which originated from a wide range of bacteria and archaea can be an adaptive bacterial immune system that mainly targets genome of bacterial invasive phages [7].

CRISPR-associated (Cas) genes are located adjacent to a CRISPR locus [8]. The CRISPR-Cas system is clustered into three major types (I, II, III) that CRISPR associated protein 9 (Cas9) is the signature gene of type II and also, the most efficient genome editing tool [9].

The Cas9 system consists of two major components including an endonuclease protein which can produce a double-strand break in DNA and two RNA components including trans-activating crRNA (tracrRNA) and mature CRISPR RNA (crRNA) which are responsible for identifying a short DNA sequence; 5'-NGG-3'; called the protospacer adjacent motif (PAM). The crRNA/tracrRNA complex associated with Cas9 creates an active ribonucleoprotein (RNP) complex [10]. In this system, crRNA can conduct the Cas9 protein as an RNA-guided endonuclease. Briefly, the crRNA 5'-end (twenty nucleotides) can interact with Guanine nucleotide of the PAM on the non-complementary DNA strand to form RNA-DNA complementarity due to the interaction between DNA backbone 5' and a phosphate-lock loop in Cas9. As mentioned above, Cas9 protein as an endonuclease protein cleaves the recognized target site to create a double-strand break (DSB) [10]. To fix this break, there have been two cellular repair mechanisms identified, including Non-Homologous End Joining (NHEJ) which joins the damaged ends of chromosomes and needs little to no DNA sequence homology.

Another mechanism is Homology Directed Repair (HDR) that has high precision to repair the DSB with the pattern of a DNA strand. For example, in humans, the NHEJ system has a higher recovery rate than the $\operatorname{HDR}[6,11,12]$.
In the CRISPR system, gRNA and Cas9 are needed to knock out or in any gene. Although there are many vectors for the gRNAs, p-Cas-Guide-EF1a-GFP CRISPR vector Origene Technologies (Rockville, MD, USA) as an all-in-one vector has both Cas9 and gRNA. Additionally, the vector contains an enhanced green fluorescent protein (EGFP) gene that can detect transfected cells. The gRNA and Cas9 protein are also under the control of the U6 promoter. For the high efficiency of gRNA transcription, U6 is an excellent housekeeping promoter, which is transcribed by RNA polymerase III [13].

One of the advantages of this system is the high and continuous transcription gRNA and Cas 9 by stable functional promoters in p-Cas-Guide-EF1a-GFP CRISPR Vector. To design DNA with high-efficiency expression by U6 promoter, guanine should be considered as the first transcribed nucleotide. In the previous studies, multi-vector systems were used to knock out or in any gene, which was costly and time-consuming. For solving this problem, we designed a single vector CRISPR system in the present study.

The objective of this study is to establish a novel method to clone gRNA in p-Cas-Guide-EF1aGFP CRISPR Vector by using BsmBI and BamHI restriction enzymes. These enzymes have specific detection sites (Bam HI: 5-GGATCC-3 and BsmBI: 5-CGTCTC (N1) -3, 3-GCAGAG (N5) -5) and also, gRNAs can be easily and quickly clone between two restrictions sites. Here, we used a one-step restriction digestion method using Esp $3 I$ and BamHI and the ligation reaction (defined as a construction procedure of one g-RNA expression vector). Additionally the main goal of designing this new system is to perform knockouts in the HSV-1 genome and study the function of essential and non-essential genes in the virus.

\section{Materials and methods}

Software selection. Designing an efficient and functional sgRNA which can accurately join to the target DNA is the first step in the CRISPR system. However, this proposed gRNA is restricted to avoid off-target sites. In this regard, there have been several software programs currently used, and are listed in Table 1.

CHOPCHOP is one of the most powerful tools used to design CRISPR/Cas9, CRISPR/Cpf1, and TALEN systems. This software supports many features in order to design genome editing systems and allows us to add the undefined genomes of organisms. A target can be mentioned in both the name of the gene and the sequence (FASTA format). 
Table 1. Several online software for gRNA design. These software are usually designed and supported by universities and research centers

\begin{tabular}{|c|c|c|c|c|}
\hline Software & СНОРСНОР & E-CRISP & Cas-OFFinder & $\begin{array}{l}\text { Genetic perturbation } \\
\text { platform web portal }\end{array}$ \\
\hline PAM & Ability to choose PAM & NGG & Different PAM & $\begin{array}{l}\text { NGG, NNGRR, TTTV } \\
\text { and enAsCas12a }\end{array}$ \\
\hline Cas & Cas9, Cas12 and Cas13 & Cas9 & $\begin{array}{l}\text { Cas9, Cas12 and MAD7 } \\
\text { nuclease }\end{array}$ & Cas9 and Cas12 \\
\hline Target genome & $\begin{array}{l}\text { It includes a large number } \\
\text { of creatures and the ability } \\
\text { to add genomes that } \\
\text { non-defined in the software }\end{array}$ & 55 Organisms & $\begin{array}{l}\text { It includes a large num- } \\
\text { ber of creatures and the } \\
\text { ability to add genomes } \\
\text { that non-defined in the } \\
\text { software }\end{array}$ & $\begin{array}{l}\text { Human } \\
\text { Mouse } \\
\text { Rat }\end{array}$ \\
\hline On target scoring & $\begin{array}{l}\text { Doench et al. } 2014 \text { [22] } \\
\text { Doench } \text { et al. } 2016 \text { [23] } \\
\text { Xu et al. } 2015 \text { [24] } \\
\text { Moreno-Mateos } \text { et al. } 2015 \text { [25] } \\
\text { Shen } \text { et al., } 2014 \text { [26] }\end{array}$ & $\begin{array}{l}\text { Xu et al., } 2015[24] \\
\text { Doench et al., } 2014 \\
{[22]}\end{array}$ & & $\begin{array}{l}\text { Doench, Fusi et al. } 2016 \text { [23] } \\
\text { Snson, et al. } 2018 \text { [27] } \\
\text { Kim, et al. } 2018 \text { [28] }\end{array}$ \\
\hline Off target scoring & Hsu et al., 2013 [29] & S-score & $\begin{array}{l}\text { Standalone command- } \\
\text {-line program [30] }\end{array}$ & $\begin{array}{l}\text { Use on target scoring for } \\
\text { off target and on target } \\
\text { prediction }\end{array}$ \\
\hline $\begin{array}{l}\text { Scientific institute } \\
\text { or university }\end{array}$ & Harvard & $\begin{array}{l}\text { German Cancer } \\
\text { Research Center }\end{array}$ & $\begin{array}{l}\text { Seoul National } \\
\text { University }\end{array}$ & Broad Institute \\
\hline Web site & http://chopchop.cbu.uib.no & $\begin{array}{l}\text { http://www.e-crisp. } \\
\text { org/E-CRISP/ } \\
\text { /designcrispr.html }\end{array}$ & $\begin{array}{l}\text { http://www.rgenome.net/ } \\
\text { cas-designer/ }\end{array}$ & $\begin{array}{l}\text { https://portals.broadinstitu- } \\
\text { te.org/ } \\
\text { gpp/public/analysis-tools/ } \\
\text { sgrna-design }\end{array}$ \\
\hline
\end{tabular}

For example, the gene name refers to the area which can be designed for the gRNA (coding region, promoter, selected exons, 3' or 5' UTR, and splice sites). Other advantages of this software include selecting the PAM sequence (for different CRISPR systems), calculating the efficiency score method, detecting off-targets in the genome, calculating the number of bases (which can be self-complementary), and choosing different gRNA backbones. Furthermore, to increase transcriptional efficiency, the promoter requires specific bases at transcription initiation. For example, for an optimal transcription by the $\mathrm{T} 7$ promoter, the two primary transcripts of the nucleotide should be GG and for the U6 promoter must be G. Also, this software can design the primers to amplify the area in which the indel mutation is created by the CRISPR system. This software can identify the restriction enzymes that are at one or more points within the replication region through the primers. In the current study, Herpes simplex virus type 1 KOS strain and human including US6 (glycoprotein D), UL39 (ribonucleotide reductase subunit 1), UL23 (Thymidine kinase), ICP34.5 and ASS1 (argininosuccinate synthase 1) were respectively selected and included into CHOPCHOP.

Cloning of gRNA. Next step, sgRNAs should be cloned in pCas-Guide-GFP vector from now on as pCasGuides. For cloning into this vector, several nucleotides
(5-GATCGNNNNNNNNNNNNNNNNNNNN $G-3$ and 5- $A A A A C$ NNNNNNNNNNNNNNNNNNNNC-3) are added to two sgRNA target ends complementary to the target region, and were ordered in two separate strands. When two oligo strands are annealed together, pre-cut sticky end of BamHI and BsmBI was established. Table 2 shows the protocol for annealing two proposed strands.

pCas-Guides CRISPR vector was cut by BamHI and BsmBI and followed by DNA clean up (Favorgen, Taiwan). Moreover, this tool can show the molar ratio of insert: vector that of 5:1 was recommended in the current study. Ligation reaction of gRNAs into double digested pCas-Guides

Table 2. Oligo annealing protocol used in the study

\begin{tabular}{|l|l|c|}
\hline $\begin{array}{l}\text { PCR program for } \\
\text { oligo annealing }\end{array}$ & $\begin{array}{c}\text { Add and mix the material } \\
\text { in a PCR tube }\end{array}$ \\
\cline { 1 - 2 } Temperature & Time & $\begin{array}{c}5 \mu \text { forward oligo }(10 \mu \mathrm{M}) \\
5 \mu l \text { reverse oligo }(10 \mu \mathrm{M}) \\
40 \mu l \text { DNase free water }\end{array}$ \\
\hline $95^{\circ} \mathrm{C}$ & $5 \mathrm{~min}$. & \\
\hline $90^{\circ} \mathrm{C}$ & $30 \mathrm{sec}$. & \\
\hline $80^{\circ} \mathrm{C}$ & $30 \mathrm{sec}$. & \\
\hline $70^{\circ} \mathrm{C}$ & $30 \mathrm{sec}$. & \\
\hline $60^{\circ} \mathrm{C}$ & $30 \mathrm{sec}$. & \\
\hline $50^{\circ} \mathrm{C}$ & $30 \mathrm{sec}$ & \\
\hline
\end{tabular}




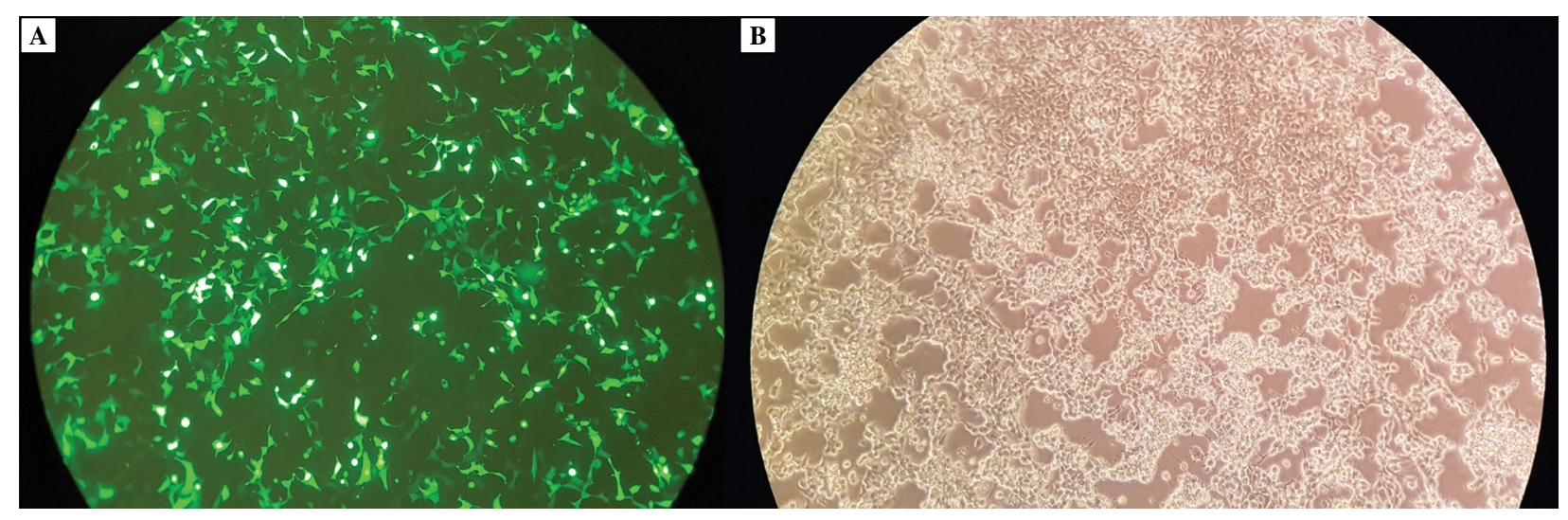

Figure 1. GFP expression of pCas-guides in HEK293-AD cells. A. Observation at $48 \mathrm{~h}$ post-transfected HEK293-AD cells. B. Control cells using an inverted fluorescent microscopy.

CRISPR vector was prepared in a $10 \mu$ l volume including $2 \mathrm{ng}$ of gRNA, $150 \mathrm{ng}$ of vector, $0.5 \mu \mathrm{l}$ of T4 ligase, and $1 \mu \mathrm{l}$ of $10 \times$ ligation buffer.

$1 \mu \mathrm{L}$ of $10 \times$ ligation buffer, $150 \mathrm{ng}$ precut $p$ Cas-Guide vector $(10 \mathrm{ng} / \mu \mathrm{L}), 5 \mathrm{ng}$ annealed double-stranded oligo (diluted), $0.5 \mu \mathrm{L}$ ligase $(0.5 \mu \mathrm{L})$, and $6.5 \mu \mathrm{L} \mathrm{dH}_{2} \mathrm{o}$ were mixed incubated for 2 hours at $22^{\circ} \mathrm{C}$. Of this, $5 \mu \mathrm{L}$ of the ligation mixture was added to competent cells.

Transfection of pCas-guide-Ef1-GFP. HEK293-AD, a derivative of the HEK293 cell line [14], was grown in a 24-well plate which contained Dulbecco's modified Eagle's medium (DMEM) (Gibco, Gaithersburg, MD, USA) supplemented with $10 \%$ fetal bovine serum (FBS) (Gibco, USA) and $100 \mathrm{IU} / \mathrm{mL}$ penicillin and $100 \mu \mathrm{g} / \mathrm{mL}$ streptomycin (Sigma-Aldrich, St. Louis, MO, USA) at $37^{\circ} \mathrm{C}$ in a humidified atmosphere containing $5 \% \mathrm{CO}_{2}$ for 48 hours. For transfection efficiency, $p$ Cas-guides were transfected using the PolyFect reagent (Qiagen, Germany). For each well, both DNA $(1,1.5$, and $2 \mu \mathrm{g})$ and PolyFect $(2,4$, and $6 \mu \mathrm{l})$ were diluted in DMEM to the final volume $100 \mu \mathrm{l}$. The complex solution was mixed and incubated for $15 \mathrm{~min}$ at room temperature, and then dropped into wells. After 5 hours, the supernatant was removed and fresh complete media was added into each well. At 24-48 hours post-transfection, expression of GFP reporter $p$ Cas-guide was examined by an inverted fluorescent microscope (Fig. 1) [15].

Virus production assay. HSV-1 genomic DNA in the supernatants from HSV-1 infected or transfected with gD gRNA was extracted by the DNA extraction kit according to the kit instructions (Favorgen, Taiwan). Relative quantitative real-time PCR for DNA of the virus was used and 2- $\Delta \Delta \mathrm{Ct}$ (CtHSV-1CtHSV-1 with gRNA treated) was applied.

The reaction contained $2 \mu \mathrm{L}$ template, $1 \mu \mathrm{L}$ ROX as a reference dye, $0.2 \mu \mathrm{M}$ probe, $0.4 \mu \mathrm{M}$ of each primer,
$10 \mu \mathrm{L}$ Qiagen Taqman Master Mix $(2 \times)$, and $5 \mu \mathrm{L}$ water. The amplification was carried out as follows: initial incubation at $95^{\circ} \mathrm{C}$ for $2 \mathrm{~min}, 35$ cycles of $10 \mathrm{~s}$ at $95^{\circ} \mathrm{C}$, and $15 \mathrm{~s}$ at $60^{\circ} \mathrm{C}$. The standard curve was drawn using ten-fold serial dilutions of HSV-1 DNA for determining the reaction efficiency. Viral DNA was amplified using a QuantiNova Probe PCR Mix kit (Qiagen, Germany). The HSV-1 primers and probe (Metabion, $\mathrm{GmbH}$, Germany) were designed to target the UL27 gene which encodes the glycoprotein B (gB) of the virus. For checking primer specificity, NCBI primer BLAST was used. The sequence and characteristics of the used oligonucleotides in this study are shown in Table 3.

To determine the virus titer, a plaque assay was performed. Vero cell monolayers in a six-well plate were infected with a serial ten-fold dilution of supernatants collected from HSV-1 infected or gRNA transfected HEK293-AD cells. After incubation for 1 hour at $37^{\circ} \mathrm{C}$, $5 \% \mathrm{CO}_{2}$, the inoculum was replaced by $2 \mathrm{X}$ DMEM with agarose $1.5 \%$ in equal volume as an overlay. Nearly $48 \mathrm{~h}$ later, cells were fixed in $4 \%$ formaldehyde and stained with $1 \%$ crystal violet (in $20 \%$ ethanol). The titer of a virus stock can be measured in plaque-forming units which is calculated by the number of plaques multiplied by dilution factor and the virus amount.

Statistical analysis. Data from the study are described as means or means \pm SD. Effects were evaluated by one-way ANOVA and Turkey's post hoc test.

\section{Results}

In the current study, g-RNA was selected based on the updated CHOPCHOP software [16], along with top rank, high cutting efficiency, minimum self-complementary, and least off-target. Furthermore, among selected g-RNAs, the low cutting efficiency g-RNA 
Table 3. The sequence and characteristics of the used oligonucleotides

\begin{tabular}{|l|c|c|c|}
\hline Oligonucleotide & Sequence & Region in gB gene & Amplicon Size \\
\hline Probe & 5'-6-FAM-ATCACCACCGTCAGCACCTTCATCG-B00HQ-1-3' & $702-726$ & $96 \mathrm{bp}$ \\
\hline Sense primer & 5'-TCCAGCATGGTGATGTTGAG-3' & $680-996$ & \\
\hline Antisense primer & 5'-CGTGTACTTCGAGGAGTACG-3' & $756-775$ & \\
\hline
\end{tabular}

Table 4. The gRNA sequences used in the current study

\begin{tabular}{|c|c|c|}
\hline g-RNA & g-RNA Forward ( $\left(\mathbf{y}^{\prime}-3^{\prime}\right)$ & g-RNA Reverse (5'-3') \\
\hline UL39.1 & GATCG $\underline{G T T G T T C C T G T C G C G A C A C A \mathrm{G}}$ & AAAACTGTGTCGCGACAGGAACAACC \\
\hline TK.1 & GATCG $\underline{G C T T G C T T G C C A A T A C G G T G \mathrm{G}}$ & AAAACCACCGTATTGGCAAGCAGCCC \\
\hline ICP34.5 & 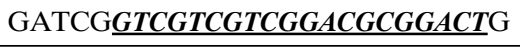 & AAAACAGTCCGCGTCCGACGACGACC \\
\hline ASS1.1 & GATCG $\underline{A C G G C G C C A C A G G A A A G G T G G}$ & AAAACCACCTTTCCTGTGGCGCCGTC \\
\hline $\mathrm{gD}$ & GATCG $\underline{G C T C C T A A A C G C A C C G T C G G \mathrm{G}}$ & AAAAC $\underline{C C G A C G G T G C G T T T A G G A G C \mathrm{C}}$ \\
\hline
\end{tabular}

$(<30)$ with each rank and off-target was eliminated. Two or three gRNAs were selected over a span of 100 to 200 nucleotides of a target gene and primers were designed up and downstream of the target gRNA position to identify any deletion or insertion. One candidate gRNA is represented in Table 4.

The used methods in this protocol were based on the creation of an single gRNA expression vectors. In fact, these vectors can be created by ligation of pre-digesting the vector backbone (Fig. 2) and annealing short oligonucleotides in a single reaction. Successful cloning using these protocols resulted in significantly more number of clones with an appropriate insert DNA as compared to no-insert control.

Clones were screened by colony PCR and confirmed by Sanger sequencing. To perform colony $\mathrm{PCR}$, the forward primer was designed based on upstream of g-RNA site, and reverse g-RNA was used as a reverse primer. The forward primer is used as a common primer. Finally, the sequencing of the clones was performed to eliminate of false-positive PCR results (Fig. 3).

\section{Virus production assay}

At first, we selected the HSV-1 KOS strain for evaluating whether the HSV-1 genome could be effectively cleaved via the CRISPR/Cas9 system. Among designed gRNAs, we selected gD gRNA to survey effect of the CRISPR-Cas9 system on the HSV-1 replication. Twenty-four hours after transfection, HEK-AD cells were infected with HSV-1 at different multiplicities of infections (MOIs), and when cyto-

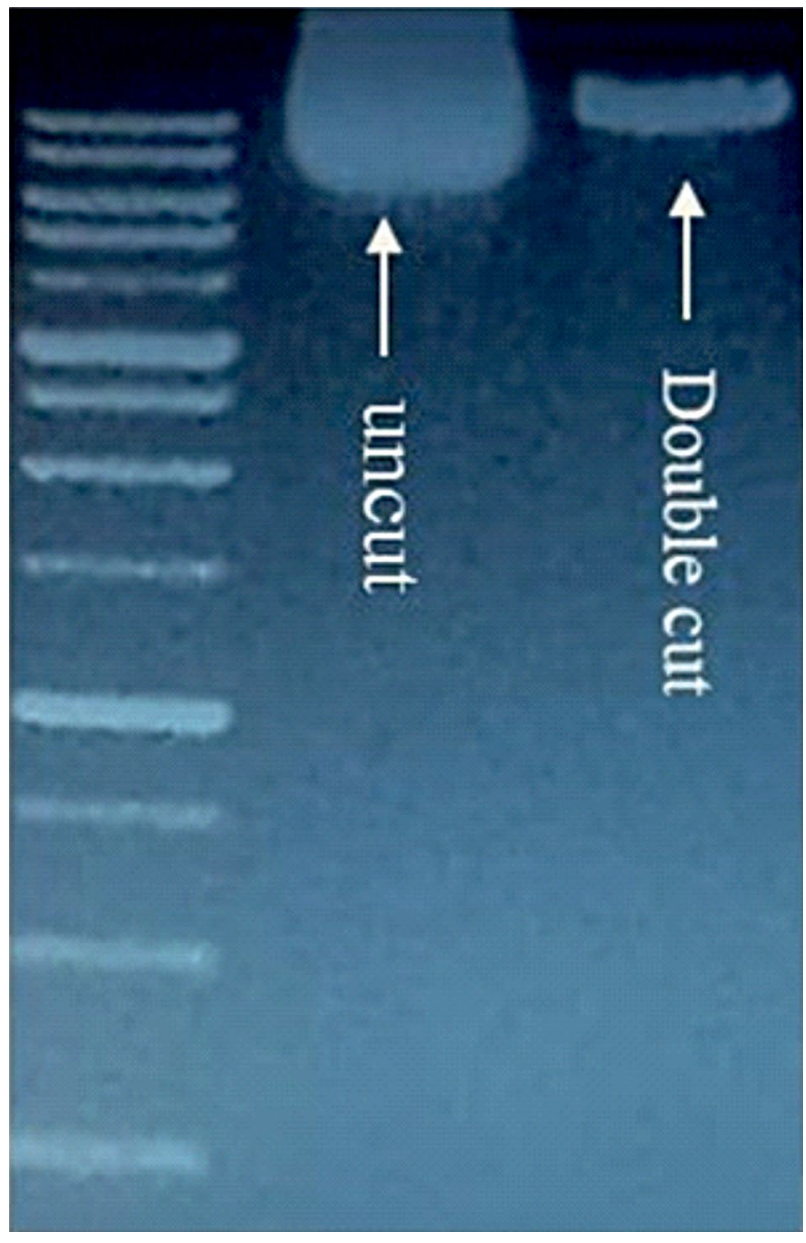

Figure 2. The digestion of a pCas-guides expression vector. $1 \%$ agarose gel was used. Lane 1: uncut pCas-guide EF1-GFP. Lane 2: pCas-guide cut with BamHI and BsmBI. 


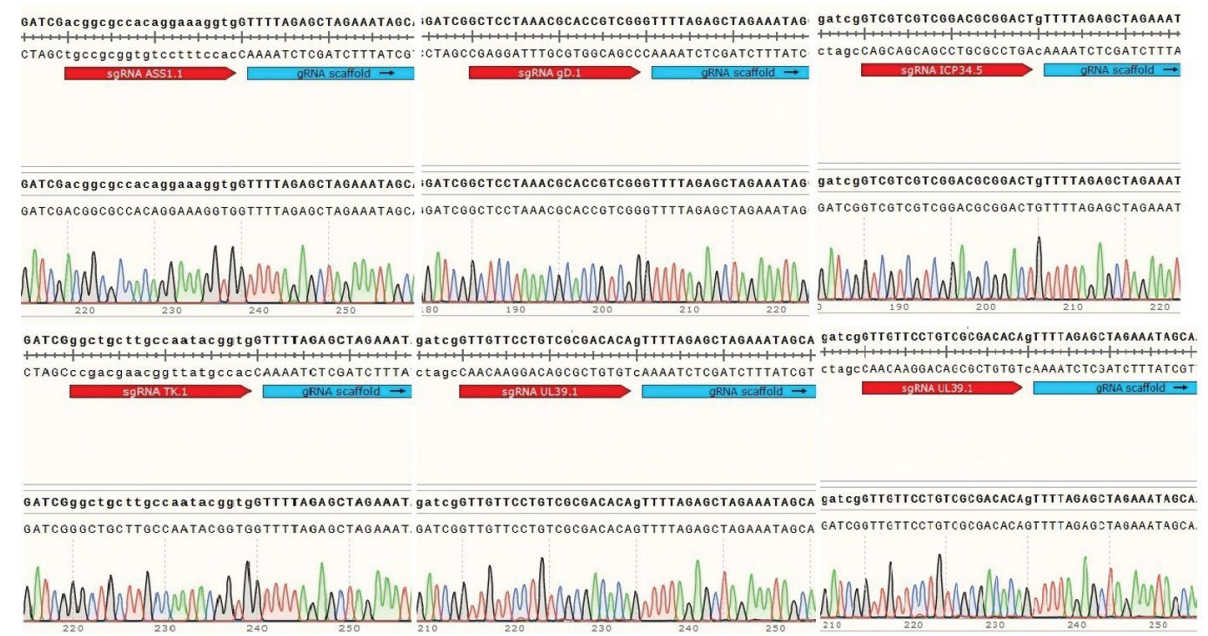

Figure 3. Sequencing of a pCas-guides g-RNA expression vector. Chromatograms corresponding to cloned g-RNA.

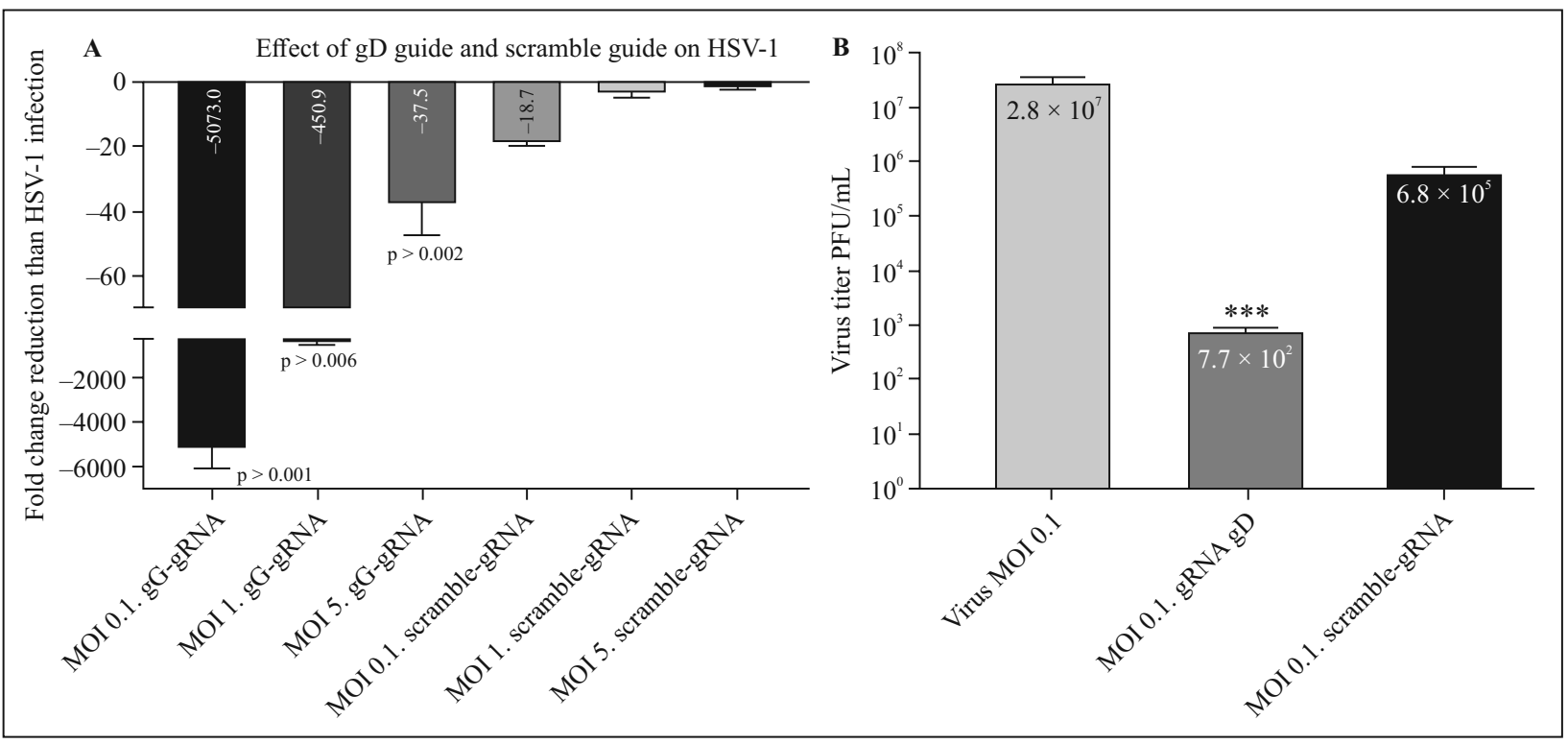

Figure. 4. The effect of gD guide on HSV-1 replication. A: by plaque assay. B: by Real Time PCR test (PFU: plaque-forming unit).

pathic effects were seen, the cells were harvested. Cytopathic effects were identified based on changes in the morphology of virus-infected HEK-AD cells after 24-48 hours. After performing a plaque assay, the CRISPR/Cas9 mediated reduction in HSV-1 infection was observed at MOI 0.1. The reduction of viral titer in this assay was computed $7.7 \times 10^{2}$ $\mathrm{PFU} / \mathrm{mL}$ (plaque-forming unit $/ \mathrm{mL}$ ) that there was a statistically significant difference. Next, we checked the efficiency of the CRISPR/Cas9 system on the effect of viral infectious dose using real-time PCR. We found an increase of CRISPR-Cas9 (gD-gRNA) efficiency with decreasing viral infectious dose from
MOI 5, 1, and 0.1 PFU/cell (Fig. 4A). In this method as in plaque assay, the decrease of HSV-1 infection was detected that there was a statistically significant difference.

The results showed that the gD gene was successfully knocked out at the infected HSV-1 into HEK-AD cells (Fig. 4B). Overall, our results showed that the CRISPR/Cas9-mediated cleavage was efficient.

\section{Discussion}

Recently, CRISPR/Cas9 technology has been used as a powerful tool in gene therapy, genetics, and genom- 
ics. In this study, we used the $p$ Cas-Guide-EF1a-GFP $C R I S P R$ vector to create a fast and efficient method for $\mathrm{gD}$ gRNA cloning by restriction enzymes (Esp3I (BsmBI) and BamHI). We demonstrated that the CRISPR/Cas9 system could efficiently knockdown the $\mathrm{gD}$ locus, resulting in different sequence mutations and disrupted $\mathrm{gD}$ expression.

Karpof et al. determined that the CRISPR/Cas9 system targeted against UL52 and UL29 genes efficiently suppressed HSV-1 reproduction in Vero cells [17]. In recent years, the CRISPR/Cas9 technology has attracted much attention due to the simplicity and cost-effectiveness of gRNA design. Nevertheless, high-throughput genomic research by this method has increased the target of many viral and cellular genes with a single vector [18].

The $\mathrm{gD}$ is an HSV-1 envelope glycoprotein that binds to several cell receptor including HVEM, NECTIN1, and 3-O-sulfated heparan sulfate [17-19]. Mutations in $\mathrm{gD}$ can reduce physical interactions with some of the HSV entry receptors and also prevent cell fusion with its receptors. $\mathrm{gD}$ acts to block the fusion of lysosomes with the endocytic vesicles [20]. Nevertheless, it has been described that the deletion of $\mathrm{gD}$ produces a marked reduction in HSV-1 secondary envelopment [21].

The expression of one g-RNA is gained using oligonucleotides comprising of the forward and reverse g-RNA target sequences (each of them has $20 \mathrm{nt}$ ) contain extra bases (gatcg) at the 5' end of the forward sequence as a Bam $\mathrm{HI}$ overhang and ' $\mathrm{G}$ ' at its 3 ' end.

The pCas-guide contains promoter RNA pol III, including U6 and $\mathrm{H} 1$ which have been used to express these small RNAs as gRNAs. It is believed that U6 promoter transcription starts at the +1 position, with $\mathrm{G}$ as the preferred initiation nucleotide [19]. To increase the efficiency of transcription site, 'aaaac' was added to the 5' end of reverse g-RNA as an Esp3I (BsmBI) cleavage site and 'c' to its 3'end as a complementary of $\mathrm{G}$ in forward g-RNA.

Esp3I is one of the Class-IIS restriction enzymes which has an asymmetric recognition site and cleavage site separately [20]. The "aaaac" sequence also as a part of g-RNA scaffold ensures the compatibility of oligo for cloning into the Esp3I (Bsm BI)-digested pCas-guide vector. The gD gRNA among designed gRNAs was selected and the effect of the CRISPR-Cas9 system was surveyed on HSV-1 replication.

To survey results of the CRISPR-Cas9 system, plaque assay and real-time PCR were performed and the outcomes of these methods confirmed the decrease in HSV-1 infection as if they had a statistically significant difference. Nevertheless, it has been revealed that insert false-positive results were obtained when the derived primers from the insert alone or span on vector in colony PCR. The probable reason can be the amplification of the unligated insert DNA or untransformed ligated present in the bacterial plate [21]. To summarize, sequencing of the p-Cas-guide vector cloned with positive colony PCR is unavoidable. These findings provide us insights for future research, and more studies are needed to better understand the CRISPR technology.

\section{Acknowledgment}

The source of data used in this paper was from the research study of Ms. Nastaran Khodadad, a student of Ahvaz Jundishapur University of Medical Sciences. This work was registered by the Ethics Committee of the Ahvaz Jundishapur University (IR.AJUMS. REC.1395.292) and financially supported by the Cancer Research Center, Ahvaz Jundishapur University of Medical Sciences, Ahvaz, Iran.

\section{Ethical Guidelines}

This article does not contain any studies with human participants or animals performed by any of the authors.

\section{Conflict of interest}

The authors declare that they have no conflict of interest.

\section{References}

1. Chen YC, Sheng J, Trang P, et al. Potential Application of the CRISPR/Cas9 System against Herpesvirus Infections. Viruses. 2018; 10(6), doi: 10.3390/v10060291, indexed in Pubmed: 29844277.

2. Fani M, Khodadad N, Ebrahimi S, et al. Zinc Sulfate in Narrow Range as an In Vitro Anti-HSV-1 Assay. Biol Trace Elem Res. 2020; 193(2): 410-413, doi: 10.1007/s12011-019-01728-0, indexed in Pubmed: 31028520.

3. Liu G, Hai R, Liu F. Detection of congenital cytomegalovirus in newborns using nucleic acid amplification techniques and its public health implications. Virol Sin. 2017; 32(5): 376-386, doi: 10.1007/s12250-017-4055-y, indexed in $\mathrm{Pu}-$ bmed: 29116590.

4. Komor AC, Kim YB, Packer MS, et al. Programmable editing of a target base in genomic DNA without double-stranded DNA cleavage. Nature. 2016; 533(7603): 420-424, doi: 10.1038/nature17946, indexed in Pubmed: 27096365.

5. Long C, McAnally JR, Shelton JM, et al. Prevention of muscular dystrophy in mice by CRISPR/Cas9-mediated editing of germline DNA. Science. 2014; 345(6201): 1184-1188, doi: 10.1126/science.1254445, indexed in Pubmed: 25123483.

6. Jinek M, Chylinski K, Fonfara I, et al. A programmable dual-RNA-guided DNA endonuclease in adaptive bacterial immunity. Science. 2012; 337(6096): 816-821, doi: 10.1126/ science.1225829, indexed in Pubmed: 22745249. 
7. Barrangou R, Marraffini LA. CRISPR-Cas systems: Prokaryotes upgrade to adaptive immunity. Mol Cell. 2014; 54(2): 234-244, doi: 10.1016/j.molcel.2014.03.011, indexed in Pubmed: 24766887.

8. Jansen R, Embden JD, Gaastra W, et al. Identification of genes that are associated with DNA repeats in prokaryotes. Mol Microbiol. 2002; 43(6): 1565-1575, doi: 10.1046/j.13652958.2002.02839.x, indexed in Pubmed: 11952905.

9. Makarova K, Koonin E. Annotation and Classification of CRISPR-Cas Systems. CRISPR. 2015: 47-75, doi: 10.1007/978-1-4939-2687-9_4.

10. Chylinski K, Makarova K, Charpentier E, et al. Classification and evolution of type II CRISPR-Cas systems. Nucleic Acids Research. 2014; 42(10): 6091-6105, doi: 10.1093/nar/gku241, indexed in Pubmed: 24728998.

11. Ran FA, Hsu PD, Wright J, et al. Genome engineering using the CRISPR-Cas9 system. Nat Protoc. 2013; 8(11): 2281-2308, doi: 10.1038/nprot.2013.143, indexed in Pubmed: 24157548.

12. Chang HHY, Pannunzio NR, Adachi N, et al. Non-homologous DNA end joining and alternative pathways to double-strand break repair. Nat Rev Mol Cell Biol. 2017; 18(8): 495-506, doi: 10.1038/nrm.2017.48, indexed in Pubmed: 28512351.

13. Chen C, Fenk LA, de Bono M. Efficient genome editing in Caenorhabditis elegans by CRISPR-targeted homologous recombination. Nucleic Acids Res. 2013; 41(20): e193, doi: 10.1093/nar/gkt805, indexed in Pubmed: 24013562.

14. Graham FL, Smiley J, Russell WC, et al. Characteristics of a human cell line transformed by DNA from human adenovirus type 5. J Gen Virol. 1977; 36(1): 59-74, doi: 10.1099/00221317-36-1-59, indexed in Pubmed: 886304.

15. Wang T, Wei JJ, Sabatini DM, et al. Genetic screens in human cells using the CRISPR-Cas9 system. Science. 2014; 343(6166): 80-84, doi: 10.1126/science.1246981, indexed in Pubmed: 24336569.

16. Labun K, Montague TG, Krause M, et al. CHOPCHOP v3: expanding the CRISPR web toolbox beyond genome editing. Nucleic Acids Res. 2019; 47(W1): W171-W174, doi: 10.1093/ nar/gkz365, indexed in Pubmed: 31106371.

17. Karpov DS, Karpov VL, Klimova RR, et al. A Plasmid-Expressed CRISPR/Cas9 System Suppresses Replication of HSV Type I in a Vero Cell Culture. Molecular Biology. 2019; 53(1): 70-78, doi: 10.1134/s0026893319010059.

18. Kabadi AM, Ousterout DG, Hilton IB, et al. Multiplex CRIS$\mathrm{PR} / \mathrm{Cas} 9$-based genome engineering from a single lentiviral vector. Nucleic Acids Res. 2014; 42(19): e147, doi: 10.1093/ nar/gku749, indexed in Pubmed: 25122746.
19. Kunkel GR, Maser RL, Calvet JP, et al. U6 small nuclear RNA is transcribed by RNA polymerase III. Proc Natl Acad Sci U S A. 1986; 83(22): 8575-8579, doi: 10.1073/ pnas.83.22.8575, indexed in Pubmed: 3464970.

20. Szybalski W, Kim SC, Hasan N, et al. Class-IIS restriction enzymes--a review. Gene. 1991; 100: 13-26, doi: 10.1016/03781119(91)90345-c, indexed in Pubmed: 2055464.

21. Zon LI, Dorfman DM, Orkin SH. The polymerase chain reaction colony miniprep. Biotechniques. 1989; 7(7): 696-698, indexed in Pubmed: 2631784.

22. Doench JG, Hartenian E, Graham DB, et al. Rational design of highly active sgRNAs for CRISPR-Cas9-mediated gene inactivation. Nat Biotechnol. 2014; 32(12): 1262-1267, doi: 10.1038/nbt.3026, indexed in Pubmed: 25184501.

23. Doench JG, Fusi N, Sullender M, et al. Optimized sgRNA design to maximize activity and minimize off-target effects of CRISPR-Cas9. Nat Biotechnol. 2016; 34(2): 184-191, doi: 10.1038/nbt.3437, indexed in Pubmed: 26780180.

24. $\mathrm{Xu} \mathrm{H}, \mathrm{Xiao} \mathrm{T}$, Chen $\mathrm{CH}$, et al. Sequence determinants of improved CRISPR sgRNA design. Genome Res. 2015; 25(8): 1147-1157, doi: 10.1101/gr.191452.115, indexed in Pubmed: 26063738.

25. Moreno-Mateos MA, Vejnar CE, Beaudoin JD, et al. CRISPRscan: designing highly efficient sgRNAs for CRISPR-Cas9 targeting in vivo. Nat Methods. 2015; 12(10): 982-988, doi: 10.1038/nmeth.3543, indexed in Pubmed: 26322839.

26. Shen B, Zhang W, Zhang J, et al. Efficient genome modification by CRISPR-Cas9 nickase with minimal off-target effects. Nat Methods. 2014; 11(4): 399-402, doi: 10.1038/nmeth.2857, indexed in Pubmed: 24584192.

27. Sanson KR, Hanna RE, Hegde M, et al. Optimized libraries for CRISPR-Cas9 genetic screens with multiple modalities. Nat Commun. 2018; 9(1): 5416, doi: 10.1038/s41467-01807901-8, indexed in Pubmed: 30575746.

28. Kim HK, Min S, Song M, et al. Deep learning improves prediction of CRISPR-Cpf1 guide RNA activity. Nat Biotechnol. 2018; 36(3): 239-241, doi: 10.1038/nbt.4061, indexed in Pubmed: 29431740.

29. Hsu PD, Scott DA, Weinstein JA, et al. DNA targeting specificity of RNA-guided Cas9 nucleases. Nat Biotechnol. 2013; 31(9): 827-832, doi: 10.1038/nbt.2647, indexed in Pubmed: 23873081.

30. Bae S, Park J, Kim JS. Cas-OFFinder: a fast and versatile algorithm that searches for potential off-target sites of Cas9 RNA-guided endonucleases. Bioinformatics. 2014; 30(10): 1473-1475, doi: 10.1093/bioinformatics/btu048, indexed in Pubmed: 24463181.

Submitted: 29 June, 2020

Accepted after reviews: 8 September, 2020 Available as AoP: 16 September, 2020 